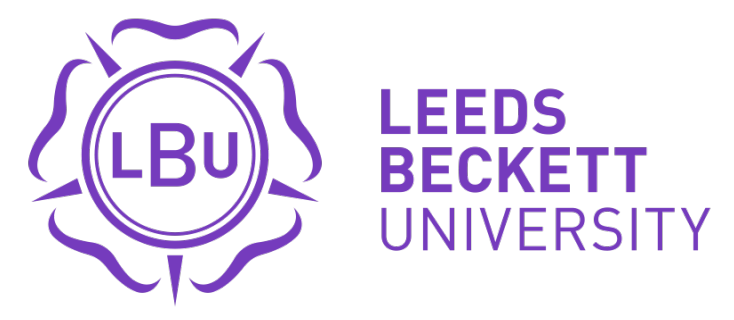

Citation:

Pardo, A and Mitjans, $A$ and Baranda, $L$ and Salamero, $M$ and McKenna, $J$ and Arteman, $A$ and Violán, M (2016) The transition of medical students through residency: Effects on physical activity and other lifestyle-related behaviors. Journal of Physical Activity and Health, 13 (5). pp. 488-493. ISSN 1543-3080 DOI: https://doi.org/10.1123/jpah.2015-0256

Link to Leeds Beckett Repository record:

https://eprints.leedsbeckett.ac.uk/id/eprint/3081/

Document Version:

Article (Accepted Version)

The aim of the Leeds Beckett Repository is to provide open access to our research, as required by funder policies and permitted by publishers and copyright law.

The Leeds Beckett repository holds a wide range of publications, each of which has been checked for copyright and the relevant embargo period has been applied by the Research Services team.

We operate on a standard take-down policy. If you are the author or publisher of an output and you would like it removed from the repository, please contact us and we will investigate on a case-by-case basis.

Each thesis in the repository has been cleared where necessary by the author for third party copyright. If you would like a thesis to be removed from the repository or believe there is an issue with copyright, please contact us on openaccess@leedsbeckett.ac.uk and we will investigate on a case-by-case basis. 


\section{The transition of medical students through residency: Effects on physical activity and other lifestyle-related behaviors.}

\section{Abstract}

Background: Little is known about lifestyle choices and preventive healthcare-seeking behaviors during the transition from medical school graduation to residency training, a period characterized by increased rates of stress and lack of free time due to demanding working conditions. All of these issues are likely to affect physical activity (PA) level. This study explored the evolution of PA and other lifestyle behaviors during this transition. Methods: A cross-sectional study and a cohort study were conducted with medical students (2010) and physicians before and after the first year of residency (2013 and 2014). A self-administered questionnaire assessed PA, health and lifestyle behaviors. Results: From a sample of 420 medical students and 478 residents, $74 \%$ comply with current PA guidelines. PA decreased by $16 \%$ during residency. Low levels of PA were found among (i) females, and in respondents who reported (ii) poor self-perceived health and (iii) unhealthy body weight $(p<0.05)$. Low PA level was also significantly associated with poor mental health in first-year residents. Conclusions: The transition has a negative effect on physicians' PA level that may affect physicians' own health and patient care. Medical programs should encourage residents to engage in PA to assure physicians' personal and mental health.

Keywords: physical activity; medical students; residents' health; lifestyle behaviors; mental health 


\section{Introduction}

In medical training the transition from medical school to residency training is characterized by higher rates of stress and a lack of free time. The demands of the working conditions can also lead to limited sleep, dealing with patients' suffering and the death and/or the responsibility of starting to make decisions regarding patients' health. ${ }^{1,2}$ Further, with increasing demands within medical education, it is important that new studies build on existing research to show the effects that the different stages of training may have on physicians' personal health and lifestyle-related behaviors.

In both patients and doctors, sedentary behaviors, physical inactivity, obesity levels, smoking rates, alcohol consumption and substance use are powerful behavioral risk factors for numerous chronic diseases. ${ }^{3,4}$ For patients, physicians are both an important source of health-related information and role models. This puts them in a powerful position to influence their patients' behaviors. ${ }^{5}$ The Toronto Charter links this influence to the key initiators of prevention actions for non-communicable diseases within healthcare systems and their capacity to influence large portions of the population. ${ }^{6}$

Recognizing that lifestyle determines health status, it is equally important that physicians have healthy lifestyles so they represent positive role; this helps to promote better patient adherence to their prescriptions. Studies show that physically active physicians and those with healthier habits are more likely to counsel their patients on lifestyle. ${ }^{5,7,8}$ Although physicians usually show better general health and lifestyle behaviors than the general population, Catalan physicians show low adherence to the current physical activity (PA) guidelines ${ }^{9}$.

Studies show the importance of both including PA prescriptions in the medical curricula and promoting healthy lifestyle choices such as PA during medical school first. Increasing the proportion of students who adopt and maintain regular PA habits is essential for increasing the rate and quality of the future PA counseling delivered by doctors. ${ }^{5} 6$ Yet little is known about the effect of the transition of graduating from medical school and starting a residency on PA level and lifestyle choices. Medical students and residents are more likely to be experiencing new, stressful situations, including extended working hours. Studies already showed the effects of the transition on stress, burnout and mental health among 
physicians-in-training. ${ }^{1,10}$ Furthermore, the lack of time due to working conditions and tiredness may be major barriers to engaging in higher levels of PA.

Addressing this lack of evidence will provide a nuanced picture of the health impact of the different stages of medical training. This allows for early detection of unhealthy behaviors and may help to design effective preventive programs. Importantly, residents' behaviors should be prioritized in this study due to their prominent role in delivering preventive and lifestyle medicine. ${ }^{11,12}$

This study aimed to explore (i) the evolution of PA level and associated factors in medical students and first-year residents, and (ii) health-related behaviors during the transition from medical school to the first year of residency training.

\section{Methods}

\section{Context}

The Galatea Foundation works to enhance the health and wellbeing of doctors. It delivers programs and projects to identify both their most sensitive groups and specific situations that pose risks. This article is framed by two previous studies by the Galatea Foundation: "Study on Health, Lifestyles and Academic Conditions of Medical Students in Catalonia: The Health of Medical Students"13 and "Longitudinal Study on Junior Doctors' Health in Catalonia (2013-2017)". ${ }^{14}$

Design

A cross-sectional study was performed to address health issues and behaviors across the early professional transition. In this study, medical students were asked to complete a standard questionnaire (2009-2010). In 2013, doctors just before beginning their first resident year ("pre-residents") were surveyed. In 2014 this same population was invited to complete a questionnaire at the end of that first year of residency.

A self-administered survey was used to obtain a representative sample of $4^{\text {th }}$ year medical students. For residents, Occupational Health Services administered the questionnaire before they started the 
residency. After the first year, an online questionnaire was sent to all participants, supplemented by telephone follow-up.

There were no incentives for participation. Care was taken to adhere to all ethical research standards, as prescribed by Spanish law, to prevent the identities of study participants from being linked to their responses (Spanish Organic Law 15/1999 dated 13 December 1999 on the Protection of Personal Data). This study is part of the Longitudinal Study on Junior Doctors' Health in Catalonia (2013-2017). ${ }^{14}$

\section{Survey}

The self-administered questionnaire was drawn from the Catalan Health Survey (ESCA). ${ }^{15,16}$ This assesses health and lifestyle habits.

Demographic data (age, gender and medical specialty) and health variables such as body mass index (BMI), smoking and alcohol consumption, and substance use such as tranquilizers, sleeping pills or marijuana were assessed using items drawn from the ESCA survey. Health status was reported through a self-perception rating, ${ }^{17}$ while mental health was obtained from the General Health Questionnaire (GHQ-12). Scores of $\geq 3$ were considered to indicate poor mental health. ${ }^{18}$ Levels of stress caused by life events was assessed using the Mitgaard List. ${ }^{19}$

Body mass index (BMI) was calculated from self-reported height and weight $\left(\mathrm{kg} / \mathrm{m}^{2}\right)$, and respondents were classified as underweight $\left(<18.5 \mathrm{~kg} / \mathrm{m}^{2}\right)$, normal weight $\left(18.5-24.9 \mathrm{~kg} / \mathrm{m}^{2}\right)$, overweight $\left(25 \mathrm{~kg} / \mathrm{m}^{2} \geq\right.$ $\left.\mathrm{BMI}<30 \mathrm{~kg} / \mathrm{m}^{2}\right)$ or obese $\left(\geq 30 \mathrm{~kg} / \mathrm{m}^{2}\right)$.

PA level was analyzed using the International Physical Activity Questionnaire (short version), ${ }^{20}$ and respondents were classified into (i) under-exercising, (ii) physically active (achieving 150 or more minutes a week of moderate PA (MPA) or 75 or more minutes of weekly vigorous PA (VPA) or an equivalent combination of MPA and VPA), and (iii) highly active (achieving 300 or more minutes a week of MPA or 150 or more minutes of weekly VPA or an equivalent combination of MPA and VPA. Individuals who did not meet the minimum recommended PA for health were categorized as underexercisers. 


\section{Analysis}

Categorical variables were described by frequencies and percentages. Differences between categorical variables (demographic- and lifestyle/health-related data) in each subsample were analyzed using chisquare test. Statistical significance was set at $p<0.05$. Statistical analysis was performed using SPSS version 18.0

\section{Results}

\section{Students}

A total of 420 students responded to the self-administered survey $(52.2 \%$ of all enrolled students; $75 \%$ women; average age $=22$ years old).

Table 1 shows the characteristics of the three samples regarding health status and health-related behaviors. This shows (i) a high prevalence of risk of poor mental health (46.7\%), and (ii) high levels of stress caused by vital life events (60.9\%). Sleep deprivation (<6h/day) was reported by $23.3 \%$ of respondents, while $24.1 \%$ reported drinking excessively. Over $80 \%$ of students reported regularly drinking, with an average of 3.6 standard drinks a week (a standard drink is a notional drink that contains a 10 gr. of ethanol). Binge drinking, defined as episodic excessive drinking (> 5 drinks per occasion), was the most common pattern of alcohol consumption.

Regarding PA level, $75 \%$ of students were meeting recommended levels of PA, mainly by walking and through VPA. The least physically active groups were (i) females (ii) students reporting poor general health and (iii) those reporting unhealthy BMI (all $p<0.01)$. Almost three-fourths of students $(74.3 \%)$ reported more than one unhealthy behavior; excessive alcohol consumption, under-exercise and smoking were the most prevalent (Table 2).

\section{Pre-residents}


The questionnaire was completed by 478 pre-residents ( $67 \%$ female) with a mean age of 26 years. Half of the residents $(49.6 \%)$ were from Catalonia, $16.3 \%$ were from other regions of Spain and $34.1 \%$ were from other countries, mainly South America. Their most prevalent specialties were related to patient care: family medicine $(29.7 \%)$, pediatrics $(8.6 \%)$, internal medicine $(6.3 \%)$ and gynecology $(6 \%)$. Other subspecialties included surgery, surgical medicine, laboratory and non-medical specialties.

Pre-residents reported high levels of self-perceived positive health and overall healthy habits. For PA, 74\% exercised at recommended levels. VPA was most associated with (i) being male, (ii) healthy BMI and reporting (iii) positive self-perceived health and (iv) good mental health ( $p<0.05$ ). Those in the surgical and medical-surgical specialties engaged in significantly more VPA than other groups of specialties. Those reporting being satisfied with their free leisure time were more likely to meet PA guidelines $(p<0.05)$.

Table 3 shows that $65.7 \%$ presented more than one unhealthy behavior; the most prevalent were under-exercise and unhealthy weight (Table 2 and 3).

\section{First-year Residents}

A response rate of $60.7 \%$ was obtained at the end of the first year of residence training $(n=290$; mean age $=27)$. These respondents reported a higher risk of poor mental health $(28.6 \%)$ and high levels of stress caused by life vital events (55.3\%). Eighty percent of residents reported one or more unhealthy behaviors; under-exercise (42.1\%) and sleep deprivation (42.4\%) were the most common issues.

Under-exercise was significantly associated with low satisfaction with personal free time and perceiving stress caused by life vital events $(p<0.05)$. VPA was positively associated with being male and reporting (i) good mental and general health, (ii) healthy BMI and (iii) low consumption of tranquilizers and sleeping pills.

\section{Transition to residency training}

Of the three groups, pre-residents presented the more optimal levels of general and mental health and positive behaviors. Medical students reported the highest levels of risk of poor mental health (46.8\%), 
excessive alcohol intake (24.1\%) and stress (60.9\%). In pre-residency, all health-related variables and lifestyle behaviors in physicians improved over life as a medical student. However, after the first year of residency, these values declined. PA was reduced; $16 \%$ fewer respondents were meeting current recommendations. Sleep deprivation and under-exercise were the most common unhealthy behaviors affecting first-year residents; nearly one in three reported poor mental health. Moreover, residents reported low satisfaction with their free time. Satisfaction was drastically reduced at the end of the first year (82.8\% satisfied at the start vs. $47.9 \%$ satisfied at the end of the first year).

Tables 2 and 3 report the prevalence of unhealthy behaviors in students, pre-residents and first-year residents. Almost three out of four students (74.3\%) and two out of three residents (65.7\%) presented more than one unhealthy behavior, including under-exercise, risky alcohol consumption, smoking, use of marijuana and tranquilizers, unhealthy weight and abnormal sleep patterns (Table 2). The prevalence of reporting more than one unhealthy behavior increased to $80 \%$ after the first year of residency. Of these, $22.8 \%$ presented more than two unhealthy behaviors. Moreover, while those reporting exercise at the recommended PA level did not present any unhealthy behaviors, under-exercised presented 2 or more unhealthy behaviors.

In students, smoking was the most prevalent toxic habit combined with other unhealthy behaviors, especially alcohol consumption, under-exercise, use of marijuana and sleeping pills and unhealthy BMI. In first-year residents, under-exercise was the most closely related to other unhealthy behaviors. The strongest correlations with under-exercise were (i) sleep deprivation (0.307), unhealthy BMI (0.243) and use of tranquilizers $(0.173)(p=0.000)$.

\section{Discussion}

This study presents original insights into the effects of the transition from medical school graduation to residency training on PA level and other lifestyle behaviors in Catalan residents. Four main findings emerge from this study. First, before starting residency a majority of students achieve current PA guidelines. Second, students and first-year residents report the highest risk of poor mental health. Third, after the first year of residency there was corresponding decrease in PA with an increase in unhealthy 
behaviors. Finally, there was an overall association between low PA levels and poor general and mental health. These results are important because $70 \%$ of the respondents specialize in patient care. Thus, the sample is representative of the physicians who will be expected to create more opportunities to promote lifestyle medicine to their patients.

The response rate of medical students (52\%) and residents (61\%) was similar to that of other studies 22,23 Even though the questionnaire was relatively long and was filled out by extremely busy individuals who work long hours. Most participants were women, which is consistent with the progressive feminization of the medical profession in Catalonia.

\section{Physical activity level}

Before residency, most junior physicians met current PA guidelines, mostly through walking and VPA. Studies show that physically active physicians felt more confident about counseling patients about PA. ${ }^{5,}$ 7, 24 However, our data showed that after the first year of residency, $16 \%$ fewer respondents $(<50 \%$ of residents) than in pre-residency engaged in recommended levels of PA. This may be explained by limited personal leisure free time and a lack of energy or tiredness attributable to long duty hours and sleep deprivation. Residents slept less than recommended, at an average of 6.6 hours per night; lack of energy may be a powerful barrier hindering them from engaging in more PA. However, surgical residents reported sleeping fewer hours per night, yet they also engaged in more VPA than any other specialty. Our results did not confirm previous results showing that the number of hours on duty was associated with decreases in $\mathrm{PA}^{25}$.

Previous literature has shown that physicians who report positive health behaviors, such as being physically active, tend to deliver more effective counseling. ${ }^{811}$ Similar to previous results on Catalan physicians, ${ }^{9}$ men and those reporting excellent health were the most likely to be active. Our results showed that PA is associated with physicians' general physical and mental health, and having sufficient leisure time is an important factor in whether they engage in PA.

Regarding PA intensities, vigorous PA (VPA) was most associated with residents' perceived health. Four in 10 residents reported exercising more at vigorous than moderate PA level. VPA was also positively 
associated with low stress and a low use of tranquilizers or sleeping pills. Walking and MPA were also significantly associated with better mental health. Moreover, being more physically active increased rates of engaging in other markers of positive health and well-being while also suppressing negative behaviors. In this understanding, PA appears to be a behavior that prevents individuals from adopting other toxic habits. For this reason, strategies on increasing PA during residency may be a valuable preventive initiative, especially to improve residents' mental health and manage sleep disorders and stress. Given their lack of leisure time, time management training may also help residents to integrate PA into their daily life.

\section{Health and Lifestyle behaviors}

\section{Students}

Students were positive role models in terms of exercising and weight control. It is satisfying that over $3 / 4$ of the students met the current PA guidelines, and $72 \%$ have a normal BMI. However, some of their behaviors were unhealthy, especially smoking, over-consumption of alcohol and inadequate hours of sleep. Students' high use of sleep medications may be related to the over-arousal caused by academic work hours or stress linked to this specific stage of training. Almost $70 \%$ of students, who go on to become important role models and health promoters in any society, need to improve some of their own lifestyle choices. More specifically, it is worrisome that almost half of the students reported poor mental health and high alcohol consumption. These results are in line with other studies ${ }^{26-28}$ and reveal that is important to address the high rates of alcohol abuse in this population.

To control the burden of lifestyle-related disease tomorrow's physicians will be increasingly expected to offer capable, competent and confident proactively promoting safe and effective PA advice in every consultation ${ }^{6}$. For this reason, it is imperative that medical curricula address exercise medicine and promote a healthy environment and behaviors in medical students. For few other student groups is this training so crucial. The university environment is important for two reasons. First, it provides formal education and can integrate lifestyle preventive medicine into the curriculum. Second, it influences students at a significant time in their lives. This development has profound effects not only during their 
time in higher education but also throughout the rest of their lives. ${ }^{29}$ It makes sense then that medical students are offered healthy educational environment that encourage and supports them in supporting more healthy habits. Moreover, it also makes sense that their professional curricula integrate lifestyle medicine in order to prepare them with the skills they need to discuss healthy habits and positive behavior change with their future patients. ${ }^{30}$

\section{Residents}

Residency is the next stage of medical training after university. It is characterized by an increase of emotional stress, a high workload and responsibility, and having to deal with difficult situations. These situations could lead to a high prevalence of burnout that negatively impacts residents' health and their capacity to adopt or sustain healthy behaviors. Our study showed a widespread increase in unhealthy behaviors after the first year of residency. Furthermore, these physicians also presented appreciably poorer general physical and mental health than at the start of that residency. Female residents had the most pressing need for PA intervention; they combined a high prevalence of poor mental health with low levels of PA.

The high prevalence of abnormally low hours of sleep per night during residency probably contributes to experiencing more on-the-job fatigue and therefore to an increase of medical errors and accidents. ${ }^{31}$ Chronic sleep deprivation and the resulting fatigue and stress are often related to other lifestyle behaviors. Residency training programs should provide regular opportunities for sleep each day to better protect patients against fatigue-related errors and to enhance the learning environment for doctors-in-training.

\section{The transition to residency}

During the different stages of medical training, we observed different patterns in physicians' health and lifestyle choices. Compared to residents just starting, medical students showed worse lifestyle behaviors. Students showed higher levels of unhealthy behaviors, including smoking, alcohol consumption and the use of substances such as tranquilizers, sleeping pills and marijuana. This may be 
related to the level of stress and pressure experienced during study for a medical degree, but it may also be related to the values and priorities that prevail at each stage of physician training.

The beginning of residency was the period when physicians presented the best level of general physical and mental health and of lifestyle behaviors. During the transition, pre-residents may experience a time where they are relaxed and have enough time to engage in PA and adopt healthy behaviors. However, this situation worsened - again - during the first year of residency. Our data showed that work conditions during the first year of residency may negatively impact residents' mental and general physical health and their health-related behaviors. The latest Medscape Physician Lifestyle Report 2015 showed that $46 \%$ of all physicians reported burnout, which is a substantial increase since the Medscape Lifestyle Report 2013.32 Moreover, burnout was associated with low PA level.

This study confirmed what many other recent studies show: that medical school and residency are peak periods of distress with a high incidence of burnout and mental disorders. ${ }^{33}$ Mental health is one of the most prevalent health problems in physicians during their early training. Yet, these issues are manageable through lifestyle medicine and interventions have been positively trialed among the most needy physicians-in-training. ${ }^{34}$ However, PA interventions have not been assessed among these intraining physicians. It is important to establish evidence regarding the cost-effectiveness of PA interventions focused on reducing risk of poor mental health and promoting well-being in students and residents.

PA promotion in residents is essential for two reasons. First, they will become role models and healthcare providers for many unhealthy patients. Second, due to the positive association between PA and mental health disorders, and because mental ill-health is currently one of the most common health problems, PA programs can concurrently enhance both physical and mental health. Managers of residency training should integrate programs that encourage PA in this group of population so it actively translates into a positive impact on patients' health. Existing evidence suggests that healthier and happier physicians deliver better preventive care for their patients.

\section{Strengths and limitations}


There are several limitations in this study. Reliance on self-reported data indicates that there may be recall and reporting biases. Over-estimation of PA or underestimation of unhealthy habits could also influence the results. The response rate may be considered low for surveys, although it matches other studies in similar samples. Likewise, survey studies that describe the non-respondents are needed. Although this was a cohort study covering the transition from medical school to residency, actually a longitudinal follow-up is being conducted in this sample population that will produce a second study. Only $50 \%$ of the students completed the second questionnaire before the residency.

This study adds to the literature on junior physicians' health and lifestyle choices. One of the strengths was the cohort design of the study. We identified how different stages of training may affect physicians' health and lifestyle behaviors. These results highlight the need to develop preventive health programs during this stage of training so that junior physicians pay more active attention to their own health and lifestyle choices. That pathway will bring healthier doctors and patients.

\section{Acknowledgments}

We would like to express our appreciation to the Galatea Foundation, which provided the database for the current study and collaborated in reviewing it. Special acknowledgment goes to all the medical students and Catalan physicians who responded, whose participation made these surveys possible.

\section{References}

1. Dabrow S, Russell S, Ackley K, Anderson E, Fabri P. Combating the stress of residency: One school's approach. Acad Med. 2006;81(5):436-9.

2. Blancafort X, Masachs, E., Valero, S., Arteman, A. Esudi sobre la salut dels residents a Catalunya. La salut del MIR. Fundació Galatea, 2008.

3. WHO. Report on the Global health risks: Mortality and burden of disease attributable to selected major risks. Geneva: WHO (World Health Organization), 2009.

4. Australian Institute of Health and Welfare. Risk factors contributing to chronic disease. In: Cat No. PHE 157, editor. Canberra. AIHW, 2012. 
5. Lobelo F, Duperly J, Frank E. Physical activity habits of doctors and medical students influence their counselling practices. Br J Sports Med 2009;43(2):89-92.

6. Gates AB. Training tomorrow's doctors, in exercise medicine, for tomorrow's patients. Brit J Sports Med. 2015.

7. Frank E, Segura C, Shen H, Oberg E. Predictors of Canadian physicians' prevention counseling practices. Can J Public Health. 2010;101(5):390-5.

8. Stanford F, Durkin M, Stallworth J, Powell C, Poston M, Blair S. Factors that influence physicians' and medical students' confidence in counseling patients about physical activity. J Prim Prev. 2014;35(3):193-201.

9. Pardo A, McKenna J, Mitjans A, Camps B, Aranda-Garcia S, Garcia-Gil J, et al. Physical Activity Level and Lifestyle-Related Risk Factors from Catalan Physicians. J Phys Act Health. 2014;11(5):922-9. doi: 10.1123/jpah.2012-0249.

10. Firth-Cozens J. Emotional distress in junior house officers. Brit Med J. 1987;295(6597):533-6.

11. Frank E, Breyan J, Elon L. Physician disclosure of healthy personal behaviors improves credibility and ability to motivate. Arch Fam Med. 2000;9:287 - 90.

12. Brotons C, Bjfrkelund C, Bulc M, Ciurana R, Godycki-Cwirko M, Jurgova E, et al. Prevention and health promotion in clinical practice: The views of general practitioners in Europe. Prev Med. $2005 ; 40: 595-601$.

13. Salamero M, Baranda, I., Mitjans, A., Baillés, E., Càmara, M., Parramon, G., Gómez, E., Arteman, A., Padrós, J. Study on health, lifestyles and academic conditions of medical students in Catalonia: The health of medical students. Fundació Galatea, 2012.

14. Mitjans A, Baranda, L., Salamero, M., Arteman, A. Fundació Galatea. Longitudinal study on junior doctors' health in Catalonia (2013-2017). Fundació Galatea. International Conference on Physician Health - Milestones and Transitions Maintaining the Balance. London, UK, 2014.

15. Generalitat de Catalunya. Enquesta de Salut de Catalunya (ESCA), 2012. Catalunya: Departament de Salut. Generalitat de Catalunya, 2012. 
16. Generalitat de Catalunya. Enquesta de Salut de Catalunya (ESCA), 2011. Catalunya: Departament de Salut, Generalitat de Catalunya, 2011.

17. Krause NM, Jay GM. What do global self-rated health items measure? Med Care. 1994;32(9):930-42.

18. Goldberg D. Manual of the General Health Questionnaire: Windsor: NFER Publishing, 1978.

19. Midtgaard M EO, Vaglum P. et al. Mental health treatment needs for medical students: A national longitudinal study. Eur Psychiatry. 2008;23:505-11.

20. Craig $C L$, Marshall $A L$, Sjostrom $M$, Bauman $A E$, Booth $M L$, Ainsworth $B E$, et al. The International Physical Activity Questionnaire (IPAQ): A comprehensive reliability and validity study in twelve countries. Med Sci Sports Exerc. 2003;35:1381 - 95.

21. SPSS Inc. Released 2009. PASW Statistics for Windows Version 18.0. Chicago: SPSS Inc.

22. Gupta G, Schleinitz MD, Reinert SE, McGarry KA. Resident physician preventive health behaviors and perspectives on primary care. Rhode Island Med J. 2013;96(5):43-7.

23. Mamo J, Fenech C. A survey of medical students attending an international student conference. Int J Collab Res Internal Med Public Health. 2012.

24. McKenna J, Naylor PJ, McDowell N. Barriers to physical activity promotion by general practitioners and practice nurses. Br J Sports Med. 1998;32(3):242-47.

25. Stanford F, Durkin M, Blair S, Powell C, Poston M, Stallworth J. Determining levels of physical activity in attending physicians, resident and fellow physicians and medical students in the USA. Brit J Sports Med. 2011.

26. Van der Veer T, Frings-Dresen M, Sluiter J. Health behaviors, care needs and attitudes towards selfprescription: A cross-sectional survey among Dutch medical students. PLOS ONE. 2011;6(11):e28038.

27. Gaspersz R, Frings-Dresen MH, Sluiter JK. Prevalence of common mental disorders among Dutch medical students and related use and need of mental health care: a cross-sectional study. Int J Adolesc Med Health. 2012;24(2):169-72.

28. Mamo J, Fenech C. A survey of medical students attending an international student conference. Int J Collab Res Internal Med Public Health. 2012;4(6):1215. 
29. Tsourus A, Dowing G, Thompson J, Dooris M. Health Promoting Universities. Concept, experience and framework for action: World Health Organization, 1998.

30. Lianov L., Johnson M. Physician competencies for prescribing lifestyle medicine. JAMA $2010 ; 14 ; 30(2): 202-3$

31. Kauppinen T. The 24-Hour Society and Industrial Relations Strategies. Oslo, Norway: European Industrial Relations Association. 2001.

32. Peckham C. Physician Burnout: It just keeps getting worse. The 2015 Medscape Physician Lifestyle Report. Medscape, 2015.

33. Dyrbye LN, West CP, Satele D, Boone S, Tan L, Sloan J, et al. Burnout among U.S. medical students, residents, and early career physicians relative to the general U.S. population. Acad Med. 2014;89(3):443-51.

34. Dacey M, Arnstein F, Kennedy MA, Wolfe J, Phillips EM. The impact of lifestyle medicine continuing education on provider knowledge, attitudes, and counseling behaviors. Med Teach. 2013;35(5):e1149-56. 
Table 1. Sample characteristics

\begin{tabular}{|c|c|c|c|}
\hline & Students (\%) & Pre-residents (\%) & $\begin{array}{c}1^{\text {st }} \text {-year } \\
\text { residents (\%) }\end{array}$ \\
\hline $\mathbf{N}$ & 420 & 478 & $\begin{array}{c}290 \\
\text { (response } \\
\text { rate= } 61 \% \text { ) }\end{array}$ \\
\hline Year & 2010 & 2013 & 2014 \\
\hline Sex, women & $75 \%$ & $67 \%$ & $68 \%$ \\
\hline Satisfaction with free time & - & 82.8 & 47.9 \\
\hline Mean age & 22 & 26 & 27 \\
\hline \multicolumn{4}{|l|}{ Lifestyle behaviors } \\
\hline \multicolumn{4}{|l|}{ PA level } \\
\hline Under-exercise & 26.4 & 27.6 & 46.1 \\
\hline Active & 26.0 & 29.0 & 45.0 \\
\hline Highly active & 42.1 & 22.8 & 35.2 \\
\hline \multicolumn{4}{|l|}{ Type of PA } \\
\hline Walking (+150 min/week) & 62.6 & 59.0 & 44.8 \\
\hline MPA + walking (+150 min/week) & 62.6 & 70.0 & 59.3 \\
\hline VPA (+75 min/week) & 40.2 & 39.0 & 34.1 \\
\hline Sedentary behavior (>6h/day) & 56.2 & 21.7 & 3.8 \\
\hline Smoking habit, smokers & 21,0 & 16.5 & 18.6 \\
\hline Alcohol consumption & 89.1 & 69.1 & 87.3 \\
\hline High risk & 24.1 & 13.0 & 16.6 \\
\hline \multicolumn{4}{|l|}{ Drugs consumption (in the last $\mathbf{3 0}$ days) } \\
\hline Marijuana & 13.8 & 6.1 & 7.2 \\
\hline Tranquilizers, sleeping pills & 11.9 & 7.3 & 9.7 \\
\hline \multicolumn{4}{|l|}{ Health } \\
\hline \multicolumn{4}{|l|}{ BMI (kg/m2) } \\
\hline Underweight $(<18.5)$ & 11.7 & 7.9 & 7.2 \\
\hline Normal weight (18.5-24.9) & 79.3 & 72.0 & 73.4 \\
\hline Overweight (25-29.9) & 7.4 & 15.1 & 14.4 \\
\hline Obesity (>30) & 0.7 & 3.3 & 4.1 \\
\hline \multicolumn{4}{|l|}{ Self-perceived health } \\
\hline Excellent/Very good & 59.5 & 70.9 & 56.9 \\
\hline Good & 33.3 & 26.8 & 38.3 \\
\hline Poor & 6.2 & 1.7 & 5.8 \\
\hline
\end{tabular}


The transition of medical students to residency

Mental health, poor

Stress level from a vital event, high level

Hours of sleep (<6h/day)
46.8

15.1

28.6

60.9

31.8

55.3

23.3

12.1

42.4 
Table 2. The prevalence of unhealthy behaviors in the student population $(n=420)$ and in the resident population (pre-residency: $n=478$; at 1st year: $n=290$ ).

\begin{tabular}{lccccccc} 
Lifestyle behaviors & $\begin{array}{c}\text { PA level, } \\
\text { under- } \\
\text { exercise }\end{array}$ & $\begin{array}{c}\text { Alcohol at } \\
\text { risk score }\end{array}$ & Smoking & $\begin{array}{c}\text { Substance } \\
\text { use, } \\
\text { marijuana }\end{array}$ & $\begin{array}{c}\text { Substance } \\
\text { use, } \\
\text { tranquilizers, } \\
\text { sleeping pills }\end{array}$ & $\begin{array}{c}\text { Over- or } \\
\text { underweight }\end{array}$ & $\begin{array}{c}\text { Low hours } \\
\text { of sleep } \\
\text { (<6h) }\end{array}$ \\
\hline & $\%$ & $\%$ & $\%$ & $\%$ & $\%$ & $\%$ & $\%$ \\
Students & 26.4 & 24.1 & 21.0 & 13.8 & 11.9 & 19.8 & 23.3 \\
Pre-residents & 26.0 & 13.0 & 16.5 & 6.1 & 7.3 & 26.3 & 12.1 \\
1st-year residents & 42.1 & 16.6 & 18.6 & 7.2 & 9.7 & 26.0 & 42.4 \\
\hline
\end{tabular}


Table 3. Classification of residents based on summed health score.

\begin{tabular}{|c|c|c|c|c|}
\hline & & $\begin{array}{c}\text { Healthy } \\
\text { (0 unhealthy } \\
\text { behaviors) }\end{array}$ & $\begin{array}{c}\text { Moderately healthy } \\
\text { (1-2 unhealthy } \\
\text { behaviors) }\end{array}$ & $\begin{array}{c}\text { Unhealthy } \\
\text { (>2 unhealthy } \\
\text { behaviors) }\end{array}$ \\
\hline & $\mathrm{n}$ & $\%$ & $\%$ & $\%$ \\
\hline Students & 420 & 25.7 & 57.6 & 16.7 \\
\hline Pre-residents & 478 & 34.3 & 55.9 & 9.8 \\
\hline 1st-year residents & 290 & 20.0 & 57.2 & 22.8 \\
\hline
\end{tabular}

